\title{
Biphenotypic acute leukemia or acute leukemia of ambiguous lineage in childhood: clinical characteristics and outcome
}

\author{
Hyun Gyung Lee ${ }^{1}$, Hee Jo Baek ${ }^{1,2}$, Ho Sung Kim ${ }^{1}$, Soo Min Park ${ }^{1}$, Tai Ju Hwang ${ }^{1}$, Hoon Kook ${ }^{1,2}$ \\ ${ }^{1}$ Department of Pediatrics, Chonnam National University Hwasun Hospital, Chonnam National University Medical School, \\ ${ }^{2}$ Environmental Health Center for Childhood Leukemia and Cancer, Chonnam National University Hwasun Hospital, Hwasun, \\ Korea
}

p-ISSN 2287-979X / e-ISSN 2288-0011 https://doi.org/10.5045/br.2019.54.1.63 Blood Res 2019;54:63-73.

Received on September 7, 2018 Revised on October 8, 2018 Accepted on November 13, 2018
Background

Acute leukemia (AL), not clearly assigned to myeloid, B-lymphoid, or T-lymphoid lineage, is classified as either biphenotypic acute leukemia (BAL) based on the European Group for Immunological Classification of Leukemias (EGIL) or acute leukemia of ambiguous lineage (ALAL) encompassing acute undifferentiated leukemia (AUL) and mixed-phenotype acute leukemia (MPAL) based on the World Health Organization (WHO) criteria.

\section{Methods}

Medical records of children newly diagnosed with BAL or ALAL, based on the EGIL or the 2008/2016 WHO criteria, respectively, admitted at Chonnam National University Hospital in 2001-2017 were retrospectively reviewed.

\section{Results}

Twelve (3.2\%) of $377 \mathrm{AL}$ patients satisfied the BAL or ALAL definitions based on the EGIL or the WHO criteria, respectively. Among 12 patients including 11 with BAL and another with undefined case based on the EGIL criteria, 7 (1.9\%) had ALAL based on more stringent 2016 WHO criteria (AUL, $2 ;$ MPAL, 5). One patient had MPAL with $t(9 ; 22)(q 34 ; q 11.2)$, $B C R-A B L+$, and two had $M L L$ gene abnormality. ALL-directed regimen was associated with better complete remission rate compared with AML-directed regimen (100.0\% vs. $16.7 \% ; P=0.015)$. The 5 -year overall survival (OS) and event-free survival (EFS) were $51.1 \pm 15.8 \%$ and $51.9 \pm 15.7 \%$, respectively. AUL was associated with poor OS and EFS compared with MPAL $(0.0 \%$ vs. $75.0 \pm 21.7 \% ; P=0.008)$.

\section{Conclusion}

Due to the rarity of the cases, future multicenter, prospective studies incorporating large number of cases are urgently warranted to identify the clinical, biologic, and molecular markers for the prediction of prognosis and determine the best tailored therapy for each patient.

Key Words Biphenotypic acute leukemia, Acute leukemia of ambiguous lineage, Mixed-phenotype acute leukemia, Children, Immunophenotyping

\section{INTRODUCTION}

Most cases of acute leukemia (AL) are classified as either myeloid or lymphoid lineage based on the expression of a set of antigens. However, there are cases of patients with blasts expressing both lymphoid and myeloid features at diagnosis, known as biphenotypic acute leukemia (BAL) or mixed-phenotype acute leukemia (MPAL) [1]. These divergent morphologic and immunophenotypic features may be uniformly present in one blast population (biphenotypic leukemia) or may be seen on distinct blast populations in a single patient (bilineal leukemia) [2].

The European Group for Immunological Classification of Leukemias (EGIL) proposed a set of diagnostic criteria for BAL. This scoring system was based on the number and degree of specificity of certain makers for myeloid or T/B lymphoid blasts [3, 4]. In 2008, the new World Health Organization (WHO) criteria were proposed for the classification of acute leukemia of ambiguous lineage (ALAL), 
which include significant modifications of the diagnostic criteria for AL of mixed phenotype. Cases with no lineage-specific markers were designated as acute undifferentiated leukemia (AUL), which often express CD34, HLA-DR, and/or CD38, and sometimes TdT, but lack specific myeloid or lymphoid antigens [5, 6]. A type of leukemia with blasts that co-expresses certain antigens of more than one lineage on the same cells or that has separate populations of blasts of different lineages is referred to as MPAL. They can be further designated as B-myeloid or T-myeloid based on flowcytometric immunophenotyping, irrespective of whether one or more than one population of blasts was found. Thus, MPAL includes both biphenotypic and bilineal ALs. These WHO criteria were more stringent than those of the EGIL criteria and relied heavily on positivity for myeloperoxidase (MPO) [5]. In 2016, the WHO classification was updated but the criteria for ALAL remained unchanged [6].

The exact incidence of BAL or ALAL in childhood is unknown. The optimal therapy for this subtype of leukemia has not been established, especially in pediatric patients. Little is known about the prognostic implications of immunophenotypes of BAL [7]. The role of hematopoietic stem cell transplantation (HSCT) in first remission remains contentious [2, 8-10].

The present study aimed to retrospectively investigate the incidence and clinicopathological characteristics of pediatric BAL or ALAL patients in Gwangju and Chonnam province from 2001 to 2017.

\section{MATERIALS AND METHODS}

\section{Patients}

From January 2001 to December 2017, the medical records of children newly diagnosed of BAL based on the EGIL criteria or ALAL based on the 2008/2016 WHO criteria who were admitted at the Chonnam National University Hospital (CNUH) and Chonnam National University Hwasun Hospital (CNUHH) were retrospectively reviewed. Patients' baseline clinicopathological data such as age, sex, blood counts, blast $\%$ in peripheral blood (PB), bone marrow (BM) morphology, immunophenotyping, and cytogenetic/molecular studies were obtained (Tables 1, 2). Treatment methods and outcome data regarding the induction chemotherapy regimen, response to chemotherapy, use of HSCT, relapse, and death were reviewed. This study was an observational, retrospective, descriptive study of the clinical aspects of childhood BAL or ALAL, which was approved by the Institutional Review Board of the CNUHH (CNUHH-2018-148).

\section{Immunophenotyping}

Immunophenotyping of $\mathrm{BM}$ aspirates was performed using the consensus method. The result was considered positive if the antigen was expressed on more than $20 \%$ (10\% for cytoplasmic markers, anti-MPO, and TdT) of leukemic cells. The panels of monoclonal antibodies used in flow cytometric immunophenotyping to detect B-cell, T-cell, and myeloid antigens as follows: myeloid lineage (anti-MPO, CD13, CD14, CD33, CD64, and CD117), megakaryocytes (CD41 and CD61), natural killer cells (CD56), lymphoid lineage (CD10

Table 1. Characteristics of the BAL or ALAL patients.

\begin{tabular}{|c|c|c|c|c|c|c|}
\hline Patient No. & $\begin{array}{l}\text { Age, } \\
\text { year/gender }\end{array}$ & $\begin{array}{c}\text { Initial WBC } \\
\left(\times 10^{9} / \mathrm{L}\right)\end{array}$ & $\begin{array}{l}\text { Initial PB } \\
\text { blast (\%) }\end{array}$ & $\begin{array}{l}\text { Initial BM } \\
\text { blast (\%) }\end{array}$ & Cytogenetics & Molecular markers \\
\hline \multicolumn{7}{|l|}{$\mathrm{B}+\mathrm{My}$} \\
\hline UPN \#1 & $10 / F$ & 10.1 & 22 & 61 & $\begin{array}{l}\text { 44-47,XX, add (1)(p36), add(3)(q28), add(4)(q34), } \\
-8,-9, \operatorname{del}(9)(\mathrm{q} 23), \operatorname{dup}(14)(\mathrm{q} 12 \mathrm{q} 32),+1-2 \mathrm{mr}\end{array}$ & NS \\
\hline UPN \#2 & $14 / F$ & 134.6 & 90 & 98 & $46, X X$ & NS \\
\hline UPN \#3 & $14 / F$ & 80.0 & 90 & 95 & $46, X X, t(1 ; 5)(p 36 ; p 13)$ & NS \\
\hline UPN \#4 & $14 / \mathrm{M}$ & 107.1 & 59 & 67 & $46, \mathrm{XY}, \mathrm{t}(9 ; 22)(\mathrm{q} 34 ; \mathrm{q} 11.2)$ & BCR-ABL+ \\
\hline UPN \# 5 & $10 / M$ & 1.8 & 0 & 85 & $47, X Y,+4, \operatorname{del}(6)(q 25)$ & NS \\
\hline UPN \#6 & $3 / \mathrm{M}$ & 11.5 & 40 & 90 & $46, X Y$ & NS \\
\hline \multicolumn{7}{|l|}{$\mathrm{T}+\mathrm{My}$} \\
\hline UPN \#7 & $0 / M$ & 2.2 & 4 & 26 & $46, X Y, t(9 ; 11)(p 22 ; q 23)$ & $\begin{array}{l}M L L \\
\text { rearrangement+ }\end{array}$ \\
\hline UPN \# 8 & $17 / M$ & 180.4 & 0 & 89 & $47, \mathrm{XY},+\mathrm{Y} / 46-49, \mathrm{XY},+21,+21,+21$ & NS \\
\hline UPN \#9 & $13 / \mathrm{M}$ & 38.0 & 0 & 34 & $46, X Y, \operatorname{del}(16)(q 10)$ & NS \\
\hline UPN \#10 & $2 / \mathrm{M}$ & 20.9 & 59 & 94 & $46, \mathrm{XY}$ & NS \\
\hline UPN \#11 & $0 / F$ & 47.0 & 43 & 33 & $47, X X,+19$ & NS \\
\hline \multicolumn{7}{|l|}{ Undefined } \\
\hline UPN \#12 & $0 / F$ & 800.9 & 96 & 96 & $46, X X, t(11 ; 19)(q 23 ; p 13.3)$ & $\begin{array}{l}M L L \\
\quad \text { rearrangement+ }\end{array}$ \\
\hline Median & 8.6 & 119.5 & 41.9 & 72.3 & & \\
\hline
\end{tabular}

Abbreviations: ALAL, acute leukemia of ambiguous lineage; B, B lymphoblastic; BAL, biphenotypic acute leukemia; BM, bone marrow; My, myeloid; T, T lymphoblastic; UPN, unique patient number; WBC, white blood cell. 
Table 2. EGIL or WHO diagnosis based on cytochemical and immunophenotype data.

\begin{tabular}{|c|c|c|c|c|c|c|c|c|}
\hline & MPO stain & Myeloid & T-lineage & B-lineage & Lymphoid & Hematopoietic & EGIL diagnosis & WHO diagnosis \\
\hline UPN \#1 & Neg & CD13, CD33, CD64 & CD7 & CD19 & CD10 & CD34/HLA-DR & $\mathrm{BAL}(\mathrm{B} / \mathrm{M})$ & ALL \\
\hline UPN \#2 & Pos $(7 \%)$ & $\begin{array}{l}\text { CD13, CD33, } \\
\text { CD117 }\end{array}$ & $\mathrm{CD} 2, \mathrm{CD} 7$ & cCD22 & & HLA-DR & $\mathrm{BAL}(\mathrm{B} / \mathrm{M})$ & AML \\
\hline UPN \#3 & Pos $(11 \%)$ & CD33, MPO & & $\begin{array}{l}\text { CD19, } \\
\text { cCD22 }\end{array}$ & TdT & CD34/HLA-DR & $\mathrm{BAL}(\mathrm{B} / \mathrm{M})$ & MPAL \\
\hline UPN \#4 & Pos $(30 \%)$ & MPO & & $\begin{array}{l}\text { CD19, } \\
\text { CCD22 }\end{array}$ & CD10/TdT & CD34 & $\mathrm{BAL}(\mathrm{B} / \mathrm{M})$ & $\begin{array}{l}\text { MPAL with } \\
\text { t(9;22); } \\
\text { BCR-ABL1 }\end{array}$ \\
\hline UPN \#5 & Pos $(11 \%)$ & CD13, CD117 & $\mathrm{CD} 2, \mathrm{CD} 7$ & cCD22 & & CD34/HLA-DR & $\mathrm{BAL}(\mathrm{B} / \mathrm{M})$ & $\mathrm{AML}$ \\
\hline UPN \#6 & Unknown & CD13, MPO & & $\begin{array}{l}\text { CD19, } \\
\text { cCD22 }\end{array}$ & CD10/TdT & HLA-DR & $\mathrm{BAL}(\mathrm{B} / \mathrm{M})$ & MPAL \\
\hline UPN \# 7 & $\mathrm{Neg}$ & CD13, CD33, CD64 & $\begin{array}{r}\text { cCD3, CD4, } \\
\text { CD8, CD7 }\end{array}$ & & & HLA-DR & $\operatorname{BAL}(\mathrm{T} / \mathrm{M})$ & $\begin{array}{l}\text { ALL with } M L L \\
\text { rearranged }\end{array}$ \\
\hline UPN \#8 & Pos $(98 \%)$ & $\begin{array}{l}\text { CD33, CD117, } \\
\text { MPO }\end{array}$ & cCD3, CD7 & & & CD34/HLA-DR & $\mathrm{BAL}(\mathrm{T} / \mathrm{M})$ & MPAL \\
\hline UPN \#9 & Unknown & CD13, CD117 & $\mathrm{CD} 2, \mathrm{CD} 7$ & & TdT & CD34/HLA-DR & $\mathrm{BAL}(\mathrm{T} / \mathrm{M})$ & AUL \\
\hline UPN \#10 & Neg & CD13, CD33 & $\mathrm{CD} 2, \mathrm{CCD} 3, \mathrm{CD} 7$ & & & CD34 & $\mathrm{BAL}(\mathrm{T} / \mathrm{M})$ & ALL \\
\hline UPN \#11 & Pos $(3 \%)$ & $\begin{array}{r}\text { CD13, CD33, } \\
\text { CD117, MPO }\end{array}$ & cCD3, CD7 & & & CD34/HLA-DR & $\mathrm{BAL}(\mathrm{T} / \mathrm{M})$ & MPAL \\
\hline UPN \#12 & Neg & & & & & CD34/HLA-DR & leukemia & $\begin{array}{l}\text { AUL with MLL } \\
\text { rearranged }\end{array}$ \\
\hline
\end{tabular}

Abbreviations: B, B lymphoid; BAL, biphenotypic acute leukemia; EGIL, european group for immunological classification of leukemias; neg, negative; pos, positive; T, T lymphoid; UPN, unique patient number; WHO, World Health Organization.

and TdT), T-lymphoid lineage (CD2, surface CD3, cytoplasmic CD3, CD4, CD8, CD5, and CD7), B-lymphoid lineage (CD19, CD20, and cytoplasmic CD22), and hematopoietic precursor (CD34 and HLA-DR).

\section{Diagnostic criteria}

The diagnostic workup of BAL was based on initial morphological, cytochemical, and immunophenotypic evaluation of the BM. Using the EGIL scoring system, BAL diagnosis was established when the score from two separate lineages was greater than $2[3,4]$.

The requirements for assigning specific lineages to the blasts were given in the 2008/2016 WHO criteria. Only a limited number of antigens were used in defining the pattern of lineage involvement. The myeloid lineage defining marker was MPO as detected by flow cytometry, immunohistochemistry, or cytochemistry; and monocytic differentiation was required for assigning diffuse positivity for non-specific esterase or expression of at least two of the following: CD11c, CD14, CD36, CD64, and lysozyme. The T-lineage defining markers were cytoplasmic CD3 or surface CD3. The B-lineage defining marker was either a strong CD19 with at least one of the strongly expressed CD79a (cytoplasmic CD22, CD10, or weak CD19) or a weak CD19 with at least two of the strongly expressed CD79a (cytoplasmic CD22 and CD10). AUL include leukemias that express no lineage specific markers. In addition, the 2008/2016 WHO classification includes certain types of MPAL harboring Philadelphia chromosome $(P h 1)$ or $M L L$ rearrangements as distinct diagnostic subgroups [5, 11-13].

\section{Treatment protocols}

Patients were initially treated with remission induction therapy of either acute lymphoblastic leukemia (ALL)- or acute myelogenous leukemia (AML)-directed chemotherapy. ALL-directed regimen was used in six patients. The Children Cancer Study Group 1882/1901 regimen based on vincristine (VCR), prednisone (PRD), and L-asparaginase (L-asp) with or without daunorubicin was used in three patients, while the Korean High Risk (HR) ALL regimen including a four-drug induction therapy was used in two since 2012. Interfant-99 hybrid regimen consisting of VCR, PRD, L-asp, and cytarabine was used in the patient with congenital leukemia (UPN \#12). For AML-directed regimen, the KSBRM induction regimen consisting of idarubicin (IDA) plus N4-behenoyl-1- $\beta$-D-arabinofuranosyl cytosine was given in three patients, while the Korean AML 2012 regimen, a double induction regimen consisting of IDA or mitoxantrone plus cytarabine based chemotherapy, was used in three.

\section{Statistical analysis}

Continuous variables were expressed as means \pm standard deviations; categorical variables were expressed as numbers and percentages. Continuous variables were compared using the Student's t-test, while categorical variables were compared using the chi-square test or Fisher's exact test. Probabilities of survival were estimated using the Kaplan-Meier (K-M) method and were compared using log-rank test. Prognostic variables were evaluated by multivariate analyses using a Cox regression proportional hazard model. A $P$-value of $<0.05$ was considered significant. The software package SPSS version 21.0 (SPSS Inc, Chicago, IL, 
USA) was used for all statistical analyses.

\section{RESULTS}

\section{Patients}

Among 377 pediatric patients diagnosed with AL, 13 satisfi ed the definition of BAL based on the EGIL criteria or ALAL based on the WHO criteria. However, a patient with secondary malignancy following chemotherapy for non-Hodgkin's lymphoma 9 years earlier was excluded; thus, only 12 primary cases (3.2\%) were finally enrolled in this study (Fig. 1). Eleven patients were diagnosed with BAL based on the EGIL criteria. The patient with UPN \#12 was excluded as it was considered an undefined case. With the more stringent 2008/2016 WHO criteria, 7 (1.9\%) patients remained as ALAL (AUL, 2; MPAL). Six BAL patients were redirected as ALL ( $\mathrm{N}=3$; UPN \#1, \#7, \#10), AML ( $\mathrm{N}=2$; UPN \#2, \#5), and AUL (UPN \#9) based on the WHO criteria (Table 2, Fig. 1).
Of 11 patients with BAL, 6 (54.5\%) had a B-lymphoid/myeloid phenotype, while 5 (45.5\%) had a T-lymphoid/myeloid phenotype based on the EGIL criteria (Table 2). Only 5 (1.3\% of the total cohort) of these patients were categorized as having MPAL according to the $2016 \mathrm{WHO}$ criteria (B-lymphoid/myeloid, 3; T-lymphoid/myeloid, 2). UPN \#4 with B-lymphoid/myeloid phenotype was reclassified as MPAL with $\mathrm{t}(9 ; 22)$ by the WHO. Likewise, UPN \#7 with T-lymphoid/myeloid was classified as MPAL with MLL rearrangement. Additionally, two patients were classified as AUL based on the WHO criteria, and one of them had $M L L$ rearrangement (UPN \#12) (Table 2).

The characteristics of patients are presented in Table 1. The median age of the patients at diagnosis was 8.6 years (range, 0 mo to $17.8 \mathrm{yr}$ ). Of the 11 patients, 7 (58.3\%) were men and 5 (41.7\%) were women. The median initial WBC count was $119.5 \times 10^{9} / \mathrm{L}$ (range, $1.8-800.9 \times 10^{9} / \mathrm{L}$ ), and four patients had WBC count higher than $100 \times 10^{9} / \mathrm{L}$. The median PB blast at diagnosis was $41.9 \%$ (range, 0-96.0\%), and the median BM blast at diagnosis was 72.3\% (range, 26.0-98.0\%).

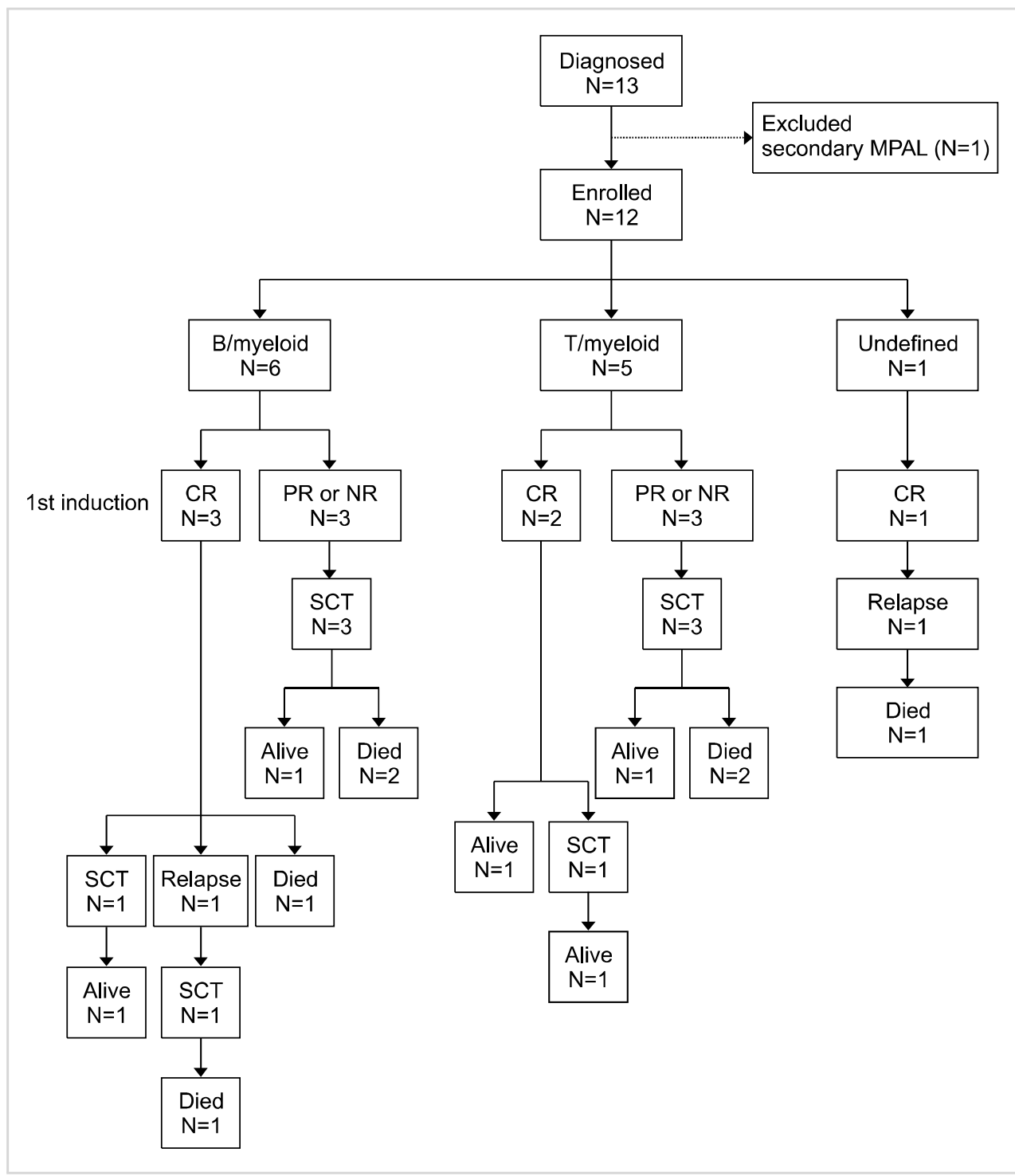

Fig. 1. Flow diagram of the classification, treatment and outcome. Abbreviations: CR, complete remission; MPAL, mixed-phenotype acute leukemia; NR, non-responders; $\mathrm{PR}$, partial remission; SCT, stem cell transplantation. 
None of the patients had CNS disease at presentation. The clinical characteristics of BAL patients with either B-lymphoid/myeloid or with T-lymphoid/myeloid phenotypes are described in Table 3.

\section{Immunophenotypic characteristics}

Table 2 shows the immunophenotypic characteristics of each BAL or ALAL patient. The expression of immunological and cytochemical markers on leukemic blasts according to BAL subtypes is summarized in Table 4 . In 12 patients with myeloid lineage disease, CD13 was positive in $8(66.7 \%)$, CD33 in 7 (58.3\%), and anti-MPO in 5 (41.7\%). The B-lymphoid lineage markers were cytoplasmic CD22 (5/12; 41.7\%), CD19 (4/12; 33.3\%), and TdT (4/12; 33.3\%). The most frequently associated positive T-lymphoid lineage marker was CD7, which was positive in all four patients (100\%). Interestingly, CD2 and CD7, T-lymphoid markers, have been aberrantly observed in B-lymphoid/myeloid cases (3/6, $50.0 \%$ ). The stem cell markers, such as HLA-DR and CD34, were positive in $10(83.3 \%)$ of 12 patients.

\section{Cytogenetic characteristics}

Results of cytogenetic analysis performed on all patients were available. Details of cytogenetic analysis and molecular studies are presented in Table 1 . In cytogenetic analysis, $3(25.0 \%)$ patients had normal karyotypes, while the remainder (75.0\%) showed a clonal abnormality. Abnormalities involving the $M L L$ gene at the 11q23 locus were found in two patients (UPN \#7 and \#12). The rest had $\mathrm{t}(9 ; 22)$ (q34;q11.2) (Ph1+) and $B C R-A B L+(\mathrm{UPN} \# 4)$.

\section{Treatment outcome}

Six patients initially received standard induction therapy for AML (KSBRM induction, 3; AML 2012 1st induction, $3)$, whereas six received ALL-directed induction therapy (CCG 1882/1901 induction, 3; Korean HR ALL induction, 2; Interfant-99 induction, 1) (Table 5). Overall, 7 (58.3\%) of 12 patients achieved complete remission (CR) after their initial induction therapy. In the AML induction group, only $1(16.7 \%)$ achieved a CR, while $2(33.3 \%)$ and $3(50.0 \%)$ had partial remission and non-remission, respectively. By contrast, all patients $(6 / 6,100.0 \%)$ achieved a CR after ALL-directed chemotherapy. Thus, ALL-directed induction chemotherapy was associated with higher chances of achieving a CR compared with AML-directed regimens (100.0\% vs. $16.7 \% ; P=0.015)$. According to BAL phenotype, the $\mathrm{CR}$ rate was similar in $\mathrm{M}+\mathrm{T}(3 / 5,60.0 \%)$ vs. in $\mathrm{M}+\mathrm{B}(3 / 6,50.0 \%$; $P=1.0)$.

Table 4. Expression of cytochemical and immunological markers in BAL.

\begin{tabular}{llll}
\hline & Total $(\%)$ & $\mathrm{B}+\mathrm{My}(\%)$ & $\mathrm{T}+\mathrm{My}(\%)$ \\
\hline Myeloid & & & \\
Anti-MPO & $5 / 12(41.7)$ & $3 / 6(50.0)$ & $2 / 5(40.0)$ \\
MPO stain & $6 / 10(60.0)$ & $4 / 5(80.0)$ & $2 / 4(50.0)$ \\
CD13 & $8 / 12(66.7)$ & $4 / 6(66.7)$ & $4 / 5(80.0 \%)$ \\
CD14 & $0 / 12(0)$ & $0 / 6(0)$ & $0 / 5(0 \%)$ \\
CD33 & $7 / 12(58.3)$ & $3 / 6(50.0)$ & $4 / 5(80.0)$ \\
CD64 & $2 / 12(16.6)$ & $1 / 6(16.7)$ & $1 / 5(20.0)$ \\
CD117 & $5 / 12(41.7)$ & $2 / 6(33.3)$ & $3 / 5(60.0)$ \\
Lymphoid & & & \\
CD10 & $3 / 12(25.0)$ & $3 / 6(50.0)$ & $0 / 5(0)$ \\
TdT & $4 / 12(33.3)$ & $3 / 6(50.0)$ & $1 / 5(0)$ \\
B-lineage & & & \\
CD19 & $4 / 12(33.3)$ & $4 / 6(66.7)$ & $0 / 5(0)$ \\
CD20 & $0 / 12(0)$ & $0 / 6(0)$ & $0 / 5(0 \%)$ \\
CCD22 & $5 / 12(41.7)$ & $5 / 6(83.3)$ & $0 / 5(0 \%)$ \\
T-lineage & & & \\
CD2 & $3 / 12(25.0)$ & $2 / 6(33.3)$ & $1 / 5(0)$ \\
CCD3 & $4 / 12(33.3)$ & $0 / 6(0)$ & $4 / 5(80.0)$ \\
CD4 & $1 / 12(8.3)$ & $0 / 6(0)$ & $1 / 5(20.0)$ \\
CD5 & $0 / 12(0)$ & $0 / 6(0)$ & $0 / 5(0)$ \\
CD7 & $8 / 12(66.7)$ & $3 / 6(50.0)$ & $5 / 5(100)$ \\
CD8 & $1 / 12(8.3)$ & $0 / 6(0)$ & $1 / 5(20.0)$ \\
Hematopoietic & & & \\
HLA-DR & $10 / 12(83.3)$ & $5 / 6(83.3)$ & $4 / 5(80.0)$ \\
CD34 & $10 / 12(83.3)$ & $4 / 6(66.7)$ & $4 / 5(80.0)$ \\
\hline
\end{tabular}

Abbreviations: B, B lymphoid; BAL, biphenotypic acute leukemia; MPO, myeloperoxidase; T, T lymphoid.

Table 3. Characteristics of the patients according to immunophenotype.

\begin{tabular}{lcccr} 
& Total $(\mathrm{N}=12)$ & $\mathrm{B}+\mathrm{My}(\mathrm{N}=6)$ & $\mathrm{T}+\mathrm{My}(\mathrm{N}=5)$ & Undefined $(\mathrm{N}=1)$ \\
\hline Age $(\mathrm{yr})$ median & $8.6(0.0-17.8)$ & $11.2(3.4-14.5)$ & $7.0(0.2-17.8)$ & 0.0 \\
$\quad$ Gender, $\mathrm{M} / \mathrm{F}$ & $7 / 5$ & $3 / 3$ & $4 / 1$ & $0 / 1$ \\
Initial WBC median $\left(\times 10^{9} / \mathrm{L}\right)$ & $119.5(1.8-800.9)$ & $57.5(1.8-134.6)$ & $57.7(2.2-180.4)$ & 800.9 \\
\% PB blast median & $41.9(0-96)$ & $50.1(0-90)$ & $21.2(0-4)$ & 96 \\
\% BM blast median & $72.3(26-98)$ & $82.6(61-98)$ & $55.2(26-94)$ & 06 \\
Cytogenetic studies & & & & 0 \\
Normal & 3 & 2 & 0 & 1 \\
Ph & 1 & 1 & 1 & 0 \\
MLL & 2 & 0 & 3 & 0 \\
Others & 6 & 3 & & \\
\hline
\end{tabular}

Abbreviations: B, B lymphoid; My, myeloid; T, T lymphoid. 
Table 5. Initial treatment, additional therapy and outcome.

\begin{tabular}{|c|c|c|c|c|c|c|c|c|}
\hline Patient No. & $\begin{array}{l}\text { Initial } \\
\text { therapy }\end{array}$ & $\begin{array}{l}\text { Initial } \\
\text { response }\end{array}$ & $\begin{array}{l}\text { Additional therapy } \\
\text { to remission }\end{array}$ & Relapse & $\begin{array}{l}\text { Post-remission } \\
\text { therapy }\end{array}$ & Outcome & OS, y & EFS, y \\
\hline \multicolumn{9}{|l|}{$\mathrm{B}+\mathrm{My}$} \\
\hline UPN \#1 & $\begin{array}{l}\text { KSBRM } \\
\text { induction }\end{array}$ & PR & FLAG-IDA & Yes & $\begin{array}{l}\text { HSCT } \\
\text { (unrelated) }\end{array}$ & Death (Candida sepsis) & 1.5 & 0.5 \\
\hline UPN \#2 & $\begin{array}{l}\text { KSBRM } \\
\text { induction }\end{array}$ & NR & FLAG-IDA & Yes (AML) & $\begin{array}{l}\text { HSCT } \\
\text { (unrelated) }\end{array}$ & Death (MRSA sepsis) & 1.8 & 1.6 \\
\hline UPN \#3 & $\begin{array}{l}\text { AML } 2012 \\
\text { 1st induction }\end{array}$ & NR & HRALL induction & No & $\begin{array}{l}\text { HSCT } \\
\text { (unrelated) }\end{array}$ & Alive & $2.4+$ & $2.4+$ \\
\hline UPN \#4 & $\begin{array}{l}\text { HR ALL } \\
\text { induction }\end{array}$ & $\mathrm{CR}$ & NA & Yes & $\begin{array}{l}\text { HR Main } \\
\text { Imatinib } \\
\text { HSCT } \\
\text { (unrelated) }\end{array}$ & Death (hepatic VOD w/AKI) & 2.1 & 1.9 \\
\hline UPN \#5 & $\begin{array}{r}\text { CCG } 1901 \\
\text { induction }\end{array}$ & CR & NA & No & Con & Death $(\mathrm{ICH})$ & 0.1 & 0.1 \\
\hline UPN \#6 & $\begin{array}{r}\text { CCG } 1882 \\
\text { induction }\end{array}$ & $\mathrm{CR}$ & NA & No & HSCT (sibling) & Alive & $9.4+$ & $9.4+$ \\
\hline \multicolumn{9}{|l|}{$\mathrm{T}+\mathrm{My}$} \\
\hline UPN \#7 & $\begin{array}{l}\text { HR ALL } \\
\text { induction }\end{array}$ & CR & NA & No & Con, Main & Alive & $7.4+$ & $7.4+$ \\
\hline UPN \#8 & $\begin{array}{l}\text { AML } 2012 \\
1 \text { st induction }\end{array}$ & CR & NA & No & $\begin{array}{l}\text { HSCT } \\
\text { (unrelated) }\end{array}$ & Alive & $1.2+$ & $1.2+$ \\
\hline UPN \#9 & $\begin{array}{l}\text { KSBRM } \\
\text { induction }\end{array}$ & NR & $\begin{array}{r}\text { CCG } 1901 \\
\text { induction }\end{array}$ & No & HSCT (sibling) & Death (acute GVHD w/AKI) & 0.5 & 0.5 \\
\hline UPN \#10 & $\begin{array}{l}\text { CCG } 1901 \\
\text { induction }\end{array}$ & CR & NA & No & $\begin{array}{l}\text { UCBSCT } \\
\text { (unrelated) }\end{array}$ & Alive & $8.3+$ & $8.3+$ \\
\hline UPN \#11 & $\begin{array}{l}\text { AML } 2012 \\
1 \text { st induction }\end{array}$ & PR & HR ALL induction & No & $\begin{array}{l}\text { UCBSCT } \\
\text { (unrelated) }\end{array}$ & Alive & $4.1+$ & $4.1+$ \\
\hline \multicolumn{9}{|l|}{ Undefined } \\
\hline UPN \#12 & $\begin{array}{l}\text { Interfant-99 } \\
\text { induction }\end{array}$ & CR & NA & Yes & FLAG-IDA & $\begin{array}{l}\text { Death (disease progression } \\
\text { after relapse) }\end{array}$ & 0.8 & 0.3 \\
\hline
\end{tabular}

Abbreviations: AKI, acute kidney injury; B, B lymphoblastic; Con, consolidation chemotherapy; CR, complete remission; GVHD, graft versus host disease; hepatic VOD, hepatic venous occlusive disease; HSCT, hematopoietic stem cell transplantation; $\mathrm{ICH}$, intracerebral hemorrhage; Main, maintenance chemotherapy; MRSA, methicillin-resistant Staphylococcus aureus; My, myeloid; NA, not applicable; NR, non-responders; PR, partial remission; T, T lymphoblastic; UCBT, umbilical cord blood transplantation; UPN, unique patient number; + , alive as of the end of 2017.

Moreover, three of five patients who failed to respond to initial AML therapy attained a CR after receiving salvage standard ALL induction therapy (UPN \#3, \#9, and \#11). The remaining two who failed to respond to AML therapy attained a CR after receiving FLAG-IDA (UPN \#1 and \#2). Thus, all 12 patients eventually achieved a CR either after initial induction or salvage induction chemotherapy.

Table 5 shows the remission induction regimens, salvage regimens, post-remission therapy, and survival outcomes of patients. Interestingly, among six patients whose diagnosis were subsequently changed from BAL, two of three patients who were initially treated with ALL-directed induction therapy survived (66\%; UPN \#7, \#10) while three who had AML-directed therapy succumbed $(0 \%$; UPN \#1, \#2, and \#9). Nine (75\%) patients eventually underwent an allogeneic HSCT [three in the first CR (CR1) after initial induction regimen (UPN \#6, \#8, and \#10), three in CR1 after salvage chemotherapy (UPN \#3, \#9, and \#11), and three in the second CR (CR2) after relapse (UPN \#1, \#2, and \#4)] (Fig. 1). Three patients did not undergo HSCT. Patients with UPN \#7 who received chemotherapy alone had continuous $\mathrm{CR}$ for over
7 years. By contrast, one patient died of intracerebral hemorrhage (UPN \#5), while the other patient had disease progression (UPN \#12).

\section{Survival rates}

At a median follow-up of 5 years (range, 0 mo-10 yr), the OS was $51.1 \pm 15.8 \%$ (Fig. $2 A$ ), and the EFS was $51.9 \pm 15.7 \%$ in 11 patients with BAL based on the EGIL criteria (Fig. 2B). Fig. 3 demonstrates the survival comparison between AUL and MPAL based on the WHO criteria. All AUL patients $(\mathrm{N}=2)$ died at 5 and 8 months after diagnosis. The 5-year OS and EFS were $0.0 \%$ in AUL and $75.0 \pm 21.7 \%$ in MPAL $(P=0.008)$ (Fig. 3A, B).

Univariate analyses of clinicolaboratory variables for the prediction of prognosis were performed on initial leukocyte count, immunophenotype $(\mathrm{M}+\mathrm{B}$ vs. $\mathrm{M}+\mathrm{T})$, cytogenetic abnormality, type of initial induction therapy (ALL directed vs. AML directed), and the use of HSCT. The initial leukocyte count $<100 \times 10^{9} / \mathrm{L}$ was associated with better 5 -year OS or 5 -year EFS (both for $62.5 \pm 17.1 \%$ vs. $0.0 \%, P=0.278$, Fig. $4 \mathrm{~A}$ and $\mathrm{B}$, respectively). T-lymphoid/myeloid BAL 


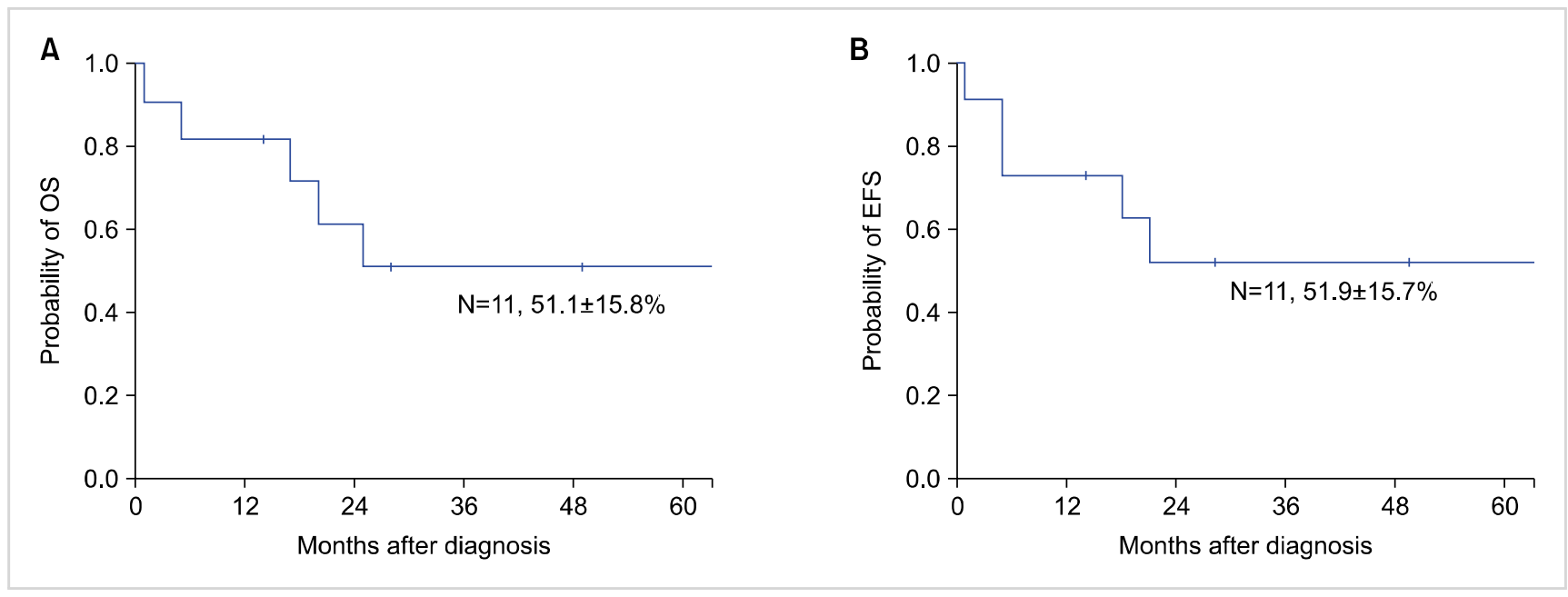

Fig. 2. The 5-year Kaplan-Meier plot for (A) OS and (B) EFS for all biphenotypic acute leukemia patients. Abbreviations: BAL, biphenotypic acute leukemia; EFS, event-free survival; OS, overall survival.

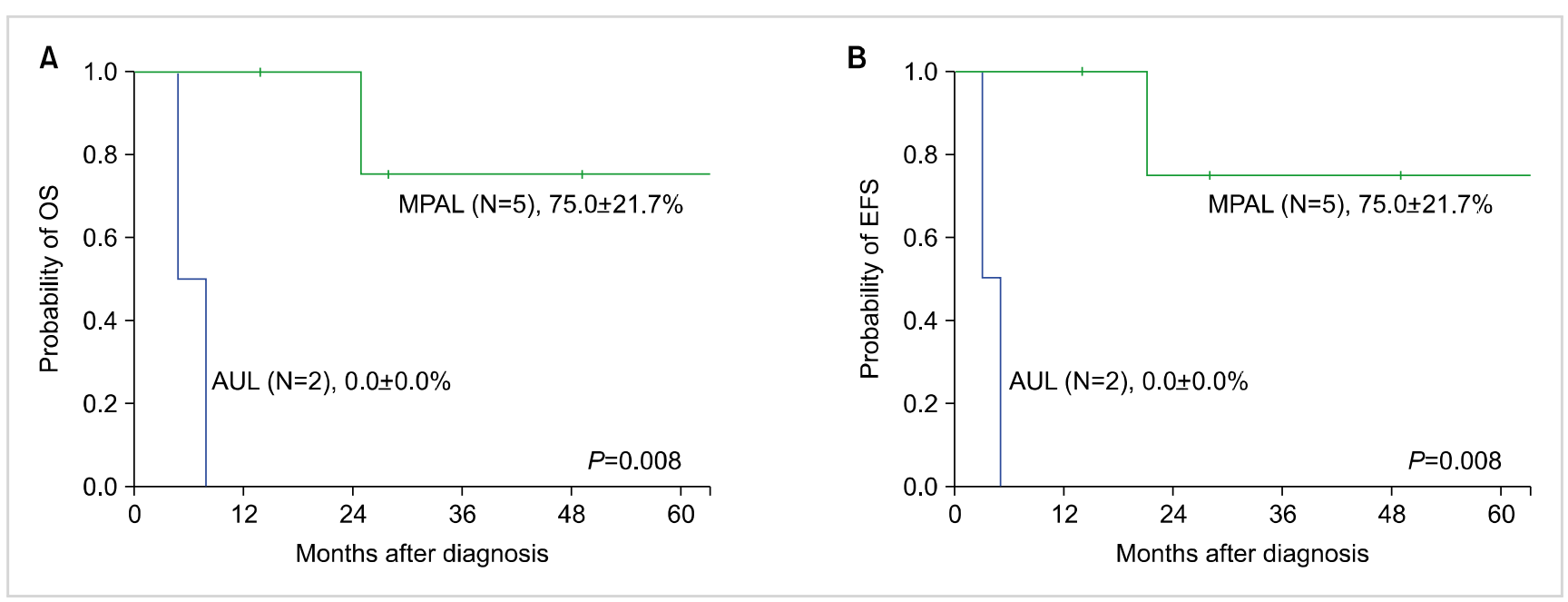

Fig. 3. The 5-year Kaplan-Meier plot of (A) OS and (B) EFS of AUL and MPAL by 2016 WHO classification.

Abbreviations: AUL, acute undifferentiated leukemia; EFS, event-free survival; MPAL, mix-phenotype acute leukemia; OS, overall survival.

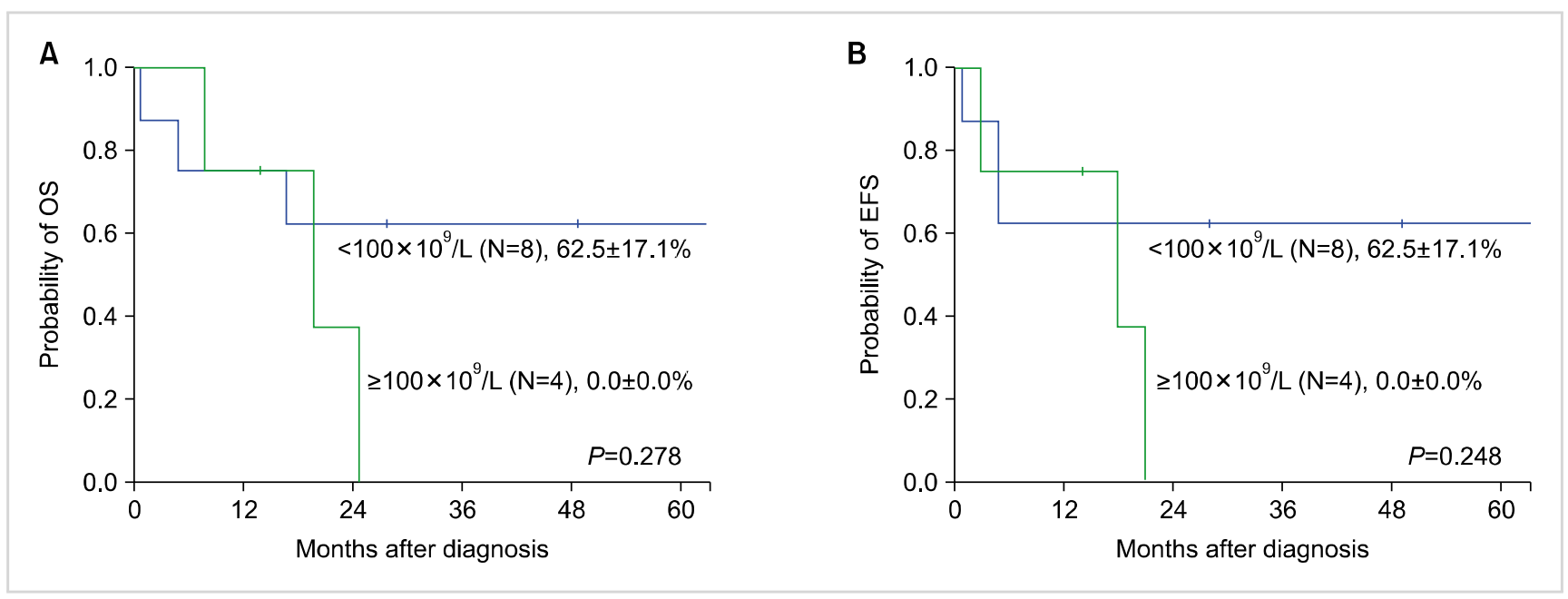

Fig. 4. The 5-year Kaplan-Meier plot of (A) OS and (B) EFS according to initial leukocyte count. Abbreviations: EFS, event-free survival; OS, overall survival. 
seemed to have a better OS and EFS than B-lymphoid/myeloid cases (both for $80.0 \pm 17.9 \%$ vs. $33.3 \pm 19.2 \%, P=0.204$, Fig. 5A and $\mathrm{B}$, respectively).

The survival rates were compared according to the type of initial induction therapy (Fig. 6). The 5-year OS probability for ALL-directed induction therapy was $50.0 \pm 20.4 \%$, while that for AML-directed induction therapy was $41.7 \pm 22.2 \%$ $(P=0.874$; Fig. 6A). The 5-year EFS for ALL-directed induction therapy was $50.0 \pm 20.4 \%$, while that for AML-directed induction therapy was $44.4 \pm 22.2 \%(P=0.995$; Fig. 6B).

The survival of all 12 patients with BAL or ALAL who underwent HSCT is shown in Fig. 7. The 5-year OS probability of patients who underwent HSCT was $50.8 \pm 17.7 \%$, while that of patients who received chemotherapy alone was $33.3 \pm 27.2 \%(P=0.316$; Fig. $7 A)$. Furthermore, the 5-year EFS of patients who underwent HSCT was $51.9 \pm 17.6 \%$, while that of patients who underwent chemotherapy alone was
33.3 $\pm 27.2 \%, \quad(P=0.224$; Fig. $7 \mathrm{~B})$.

Among nine patients who underwent HSCTs, six were transplanted in CR1, and three in CR2 after relapse. Patients who underwent HSCT in CR1 appeared to have a better OS and EFS than those in CR2 (both for $83.3 \pm 15.2 \%$ vs. $0.0 \%$, Fig. 8A, $P=0.064$; Fig. $8 \mathrm{~B}, P=0.04$, respectively).

\section{DISCUSSION}

The incidence of BAL or ALAL varies according based on the criteria (EGIL or 2016 WHO) used for the diagnosis. BAL is reported to account for $2-5 \%$ of all ALs based on the EGIL criteria, while ALAL $1-2.5 \%$ based on the WHO criteria [2, 9, 14], which are similar to the current study of $2.9 \%$ and $1.9 \%$, respectively. Additionally, the incidence of AUL and MPAL among ALAL was $0.5 \%$ and $1.3 \%$, re-
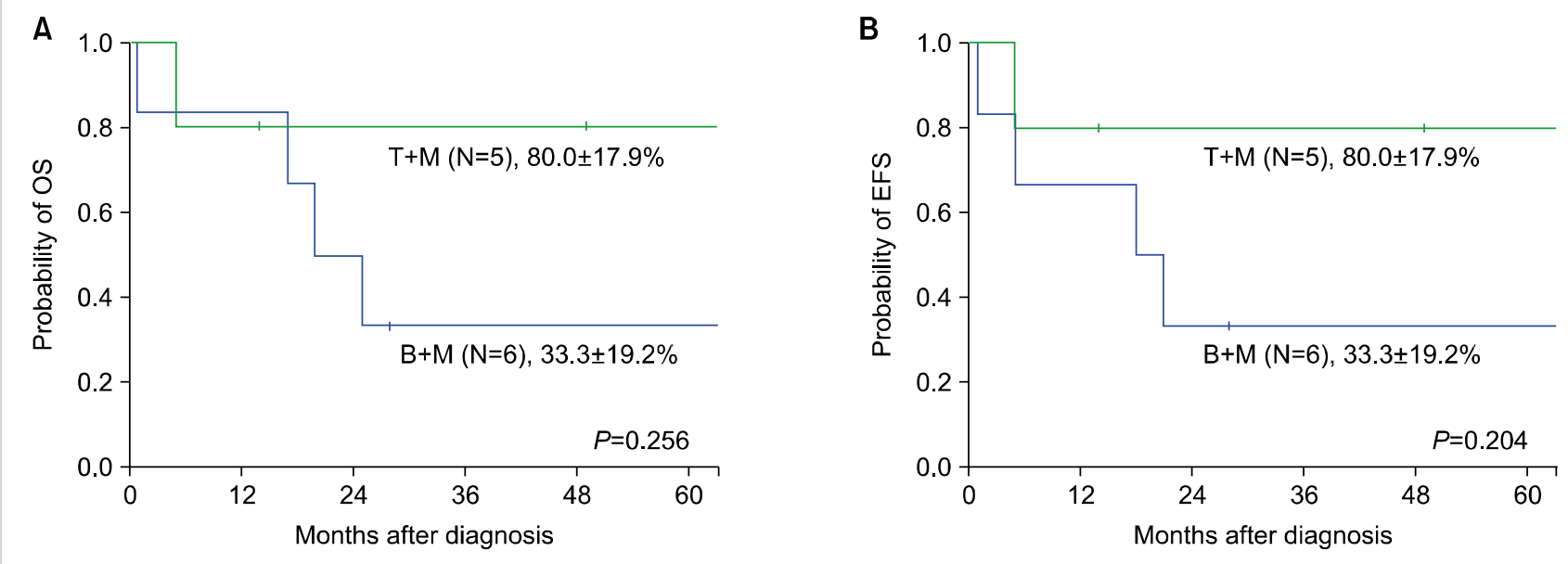

Fig. 5. The 5-year Kaplan-Meier plot of (A) OS and (B) EFS for patients with T/myeloid and B/myeloid biphenotypic leukemia. Abbreviations: EFS, event-free survival; OS, overall survival.

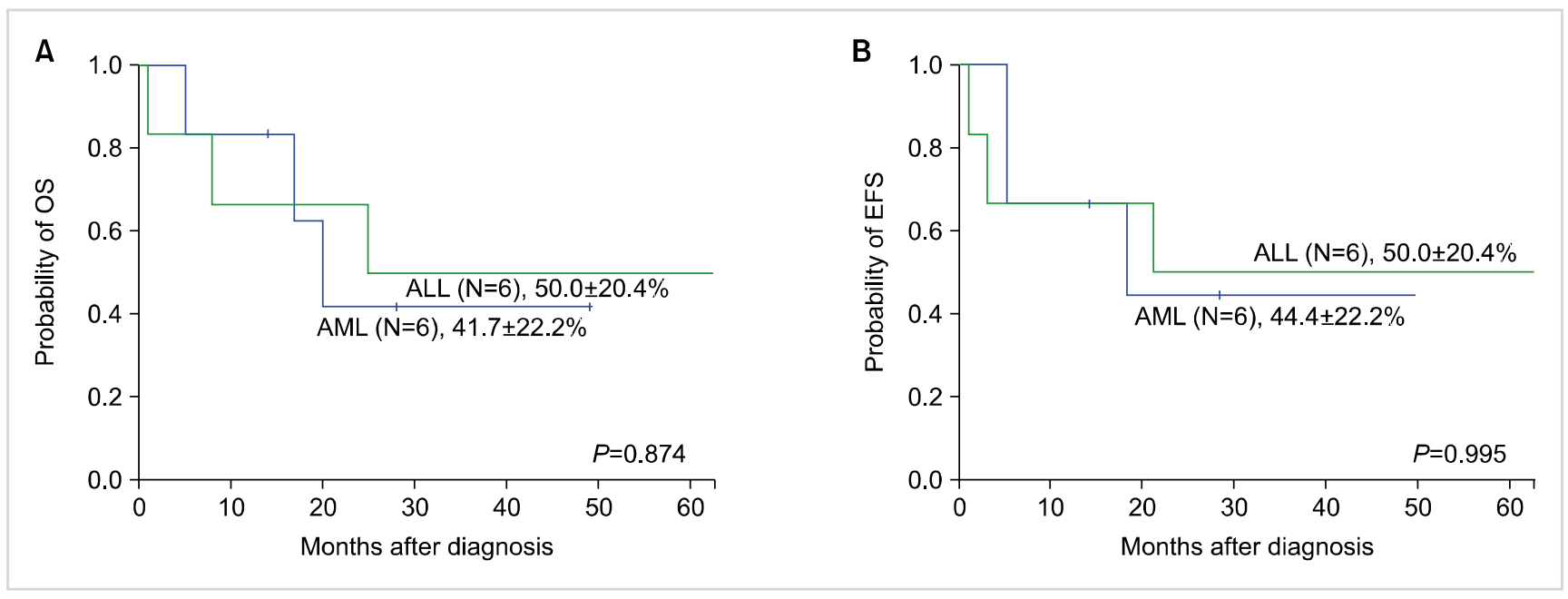

Fig. 6. The 5-year Kaplan-Meier plot for (A) OS and (B) EFS for biphenotypic acute leukemia patients treated with ALL-directed induction therapy and AML-directed induction therapy.

Abbreviations: EFS, event-free survival; OS, overall survival. 

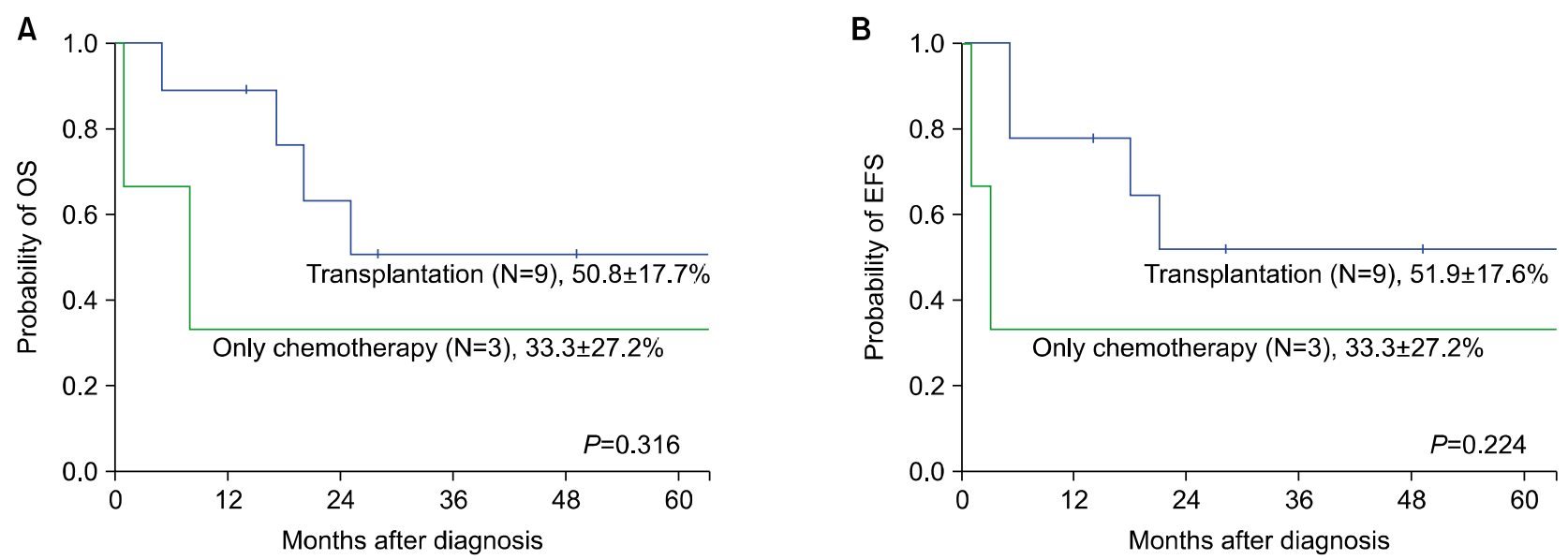

Fig. 7. The 5-year Kaplan-Meier plot for (A) OS and (B) EFS for biphenotypic acute leukemia patients treated with chemotherapy alone and those treated with HSCT in first remission.

Abbreviations: EFS, event-free survival; HSCT, hematopoietic stem cell transplantation; OS, overall survival.
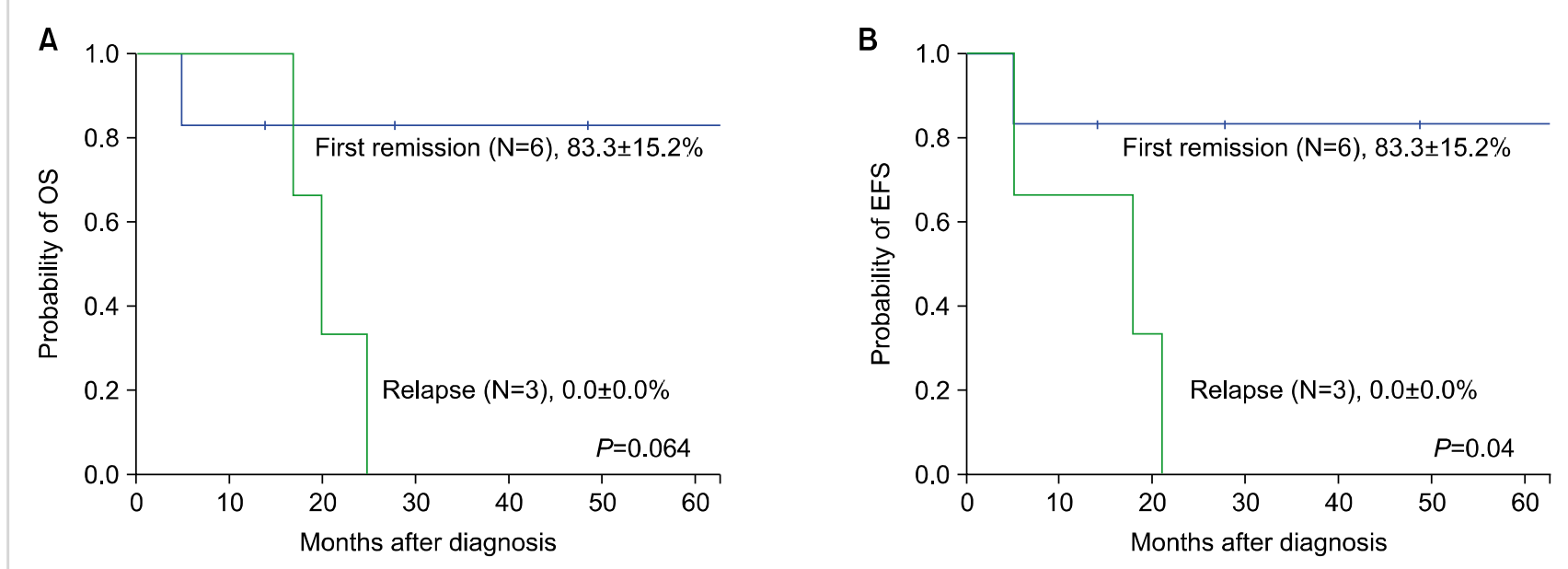

Fig. 8. The 5-year Kaplan-Meier plot for (A) OS and (B) EFS for biphenotypic acute leukemia patients treated with HSCT in first remission and those treated with HSCT in the second remission after relapse.

Abbreviations: EFS, event-free survival; HSCT, hematopoietic stem cell transplantation; OS, overall survival.

spectively, in this study. Although the incidence was not clearly defined, the incidence of AUL was reported to be $0.2-1 \%$ in some studies $[15,16]$.

In contrast to the EGIL approach of scoring a detailed blast immunophenotype with numerous markers, the WHO criteria emphasize a few key lineage-defining markers with particular emphasis on CD19 for B lineage, CD3 for T lineage, and MPO for myeloid lineage. The WHO approach is simpler but relies heavily on the sensitivity and specificity of a few markers. Moreover, the WHO classification does not specify thresholds for positivity of these key markers, leaving it up to individual laboratories to decide on the definition of significant expression [13]. In addition, the WHO diagnostic criteria defined AUL as a type of leukemia that does not involve the expression of those specific antigens and hence set up the classification of ALAL, including MPAL and AUL. In the present study, the incidence might have been underestimated as some immunological markers such as cyCD79a were not tested in our institute.

The phenotype distribution in our patients was no different from those reported in previously published studies. The number of patients having the B-lymphoid/myeloid phenotype was more than the number of patients having the T-lymphoid/myeloid phenotype $[2,17]$. In adult studies, more than $70 \%$ of BAL patients had the B-lymphoid/myeloid phenotype, whereas only $23-33 \%$ had the T-lymphoid/myeloid phenotype. The B-lymphoid/T-lymphoid/myeloid phenotype and B-lymphoid/T-lymphoid phenotype were extremely rare [7, 18-20].

In the WHO 2016 diagnostic criteria, $\mathrm{t}(9 ; 22) / P h+$ positive and $M L L$ rearrangement were classified separately. Although MPAL was not associated with a consistent cytogenetic/mo- 
lecular abnormality, the Philadelphia chromosome was the most common abnormality, with $17-41 \%$ incidence in BAL and MPAL patients with almost exclusively B-lymphoid/myeloid phenotype $[7,14,21] . B C R-A B L 1$ was more common among adult MPAL patients (15\%) than among pediatric MPAL patients (3\%) [14, 15, 22]. However, all $P h+$ patients should be identified as quickly as possible because they may benefit from the addition of tyrosine kinase inhibitors (TKI) same as those with $P h+$ ALL [12, 23, 24].

The second most common cytogenetic abnormality was $M L L$ rearrangement as reported in other studies. Its incidence ranged from $10 \%$ to $15 \%[7,8,14]$ and were higher in the pediatric age group than in the adult group (15\% vs. $3 \%)[14,15,25]$. In the present study, the incidence of cytogenetic abnormality was also $16.7 \%$. No single chromosomal abnormality is unique to ALAL. However, the present data and those of other studies showed that structural abnormalities are common.

MPALs may have worse prognosis than other types of leukemia. The proposed reasons were as follows: the mixed-phenotype leukemic stem cells are chemoresistant owing to slow replication, the blasts can adapt to therapy by switching phenotype, and some MPALs express high levels of multidrug resistance proteins [12, 26].

Because selection of an anti-leukemic chemotherapy regimen for AL is largely based on whether a case is classified as myeloid or lymphoid, the presence of markers for both lineages may have important implications for treatment. Thus, there are no agreed chemotherapy protocols for patients with ALAL as yet $[12,27]$. In the current study, the induction regimen was selected based on the morphology of the blasts and cytochemical stains. All 6 (100.0\%) patients who underwent ALL induction therapy reached a CR. On the contrary, among six patients who received AML induction therapy along, 1 (16.7\%) achieved a CR after one cycle, while 2 achieved a CR after FLAG-IDA salvage chemotherapy. The remaining three patients reached a CR after switching to ALL induction therapy. Thus, the current study demonstrated that an ALL-directed induction chemotherapy is more effective in achieving CR than AML-type therapy, although patient numbers are small and follow-ups are not long. Rubnitz et al. [2] reported that ALL-type therapy was associated with higher CR rate than AML-type induction therapy ( $83 \%$ vs. 52\%, respectively). Similar results were documented from studies by Matutes et al. [14] and by Al-Seraihy et al. [17]. In a Korean pediatric study, a significantly lower CR rate of $52 \%$ was reported even predominantly with ALL-type therapy. In this study, eight of ten patients who failed to achieve a CR with AML-type therapy subsequently entered a CR with ALL-type induction therapy [8]. Gerr et al. [15] reported significantly better survival in patients who received ALL-type induction therapy than those with AML-type induction therapy (81\% vs. $41 \%$, $P=0.0009)$. In this study, same tendency was observed but they were not significantly different.

The issue of HSCT remains contentious. In this study, among 9 (75\% of total cohort) patients who received an allogeneic HSCT, 5 (55.5\%) survived. Among three patients who did not receive HSCT, only one survived. Our decision to proceed with transplant was primarily based on the availability of HLA-matched stem cell donor. The current study demonstrated a favorable outcome for patients transplanted in CR1. The post-allogeneic-HSCT outcome was much better than with post remission chemotherapy in a single institution ( $\mathrm{N}=32$, 3-year OS $77 \%$ vs. 16\%) [28]. However, a Korean pediatric study reported no benefit from HSCT over chemotherapy alone in patients with BAL [8]. In general, similar outcomes have been reported between transplanted vs. non-transplanted cases, but the issues need to be clarified because of the lack of randomized study, due the small number and heterogeneity of patients, stem cell donor, and transplantation procedures. Thus, routine use of HSCT may not be required in patients with ALAL, especially in those who attain a molecular remission after induction therapy. However, still a significant portion of the patients may need a prompt HSCT. Some recommend that an HSCT should be reserved for the case of Philadelphia chromosome-positive MPAL, infants particularly those with 11q23 abnormalities and those who have a poor response to early therapy [28, 29]. However, whether older children with 11q23 abnormalities should also be transplanted remains unclear and require further evaluation using larger, possibly multi-institutional studies. Other risk-determining variables need to be included in this decision process $[10,12,29]$.

So far, the survival rate reported in both pediatric and adult studies ranged from $8.1 \%$ to $60 \%[2,17,30]$. In the current study, the 5-year OS of the total cohort was $51.1 \pm 15.8 \%$. Most recently, the survival rate of MPAL based on the WHO classification was about $80 \%$ in children [16]. Killick et al. showed a better OS for the younger patients than older counterparts ( $75 \%$ vs. $17 \%$ at $2 \mathrm{yr} ; P=0.01$ ) [7]. Gerr et al. [15] demonstrated that the 5-year EFS probability of ALAL patients $(62 \pm 5 \%)$ was lower than those of ALL patients $(80 \pm 1 \%, P<0.001)$, but better than those of AML patients $(49 \pm 2 \%, P=0.027)$. A few studies demonstrated the survival of AUL or its comparison with MPAL, because of the extreme rarity of the cases. In the current study, the survival of MPAL $(75.0 \pm 21.7 \%)$ was better than that of AUL $(0.0 \%)(P=0.008)[30]$.

The prognostic implication of high leukocyte counts at diagnosis, and immunophenotypic subtype, expression of the specific antigen, as well as the selection of induction regimen and the use of HSCT in BAL or ALAL need to be further established in prospective, multicenter fashion. Pediatric ALAL may be distinct from its adult counterpart in terms of clinical and cytogenetic characteristics, and response to chemotherapy, even though they are extremely rare. With better understanding of novel mechanism and pathogenesis of these rare situations, the best therapeutic approaches including target therapy will be available in the future. 


\section{Authors' Disclosures of Potential Conflicts of Interest}

No potential conflicts of interest relevant to this article were reported.

\section{REFERENCES}

1. Béné MC, Porwit A. Acute leukemias of ambiguous lineage. Semin Diagn Pathol 2012;29:12-8.

2. Rubnitz JE, Onciu M, Pounds S, et al. Acute mixed lineage leukemia in children: the experience of St Jude Children's Research Hospital. Blood 2009;113:5083-9.

3. Bene MC, Castoldi G, Knapp W, et al. Proposals for the immunological classification of acute leukemias. European Group for the Immunological Characterization of Leukemias (EGIL). Leukemia 1995;9:1783-6.

4. Matutes E, Morilla R, Farahat N, et al. Definition of acute biphenotypic leukemia. Haematologica 1997;82:64-6.

5. Vardiman JW, Thiele J, Arber DA, et al. The 2008 revision of the World Health Organization (WHO) classification of myeloid neoplasms and acute leukemia: rationale and important changes. Blood 2009;114:937-51.

6. Arber DA, Orazi A, Hasserjian R, et al. The 2016 revision to the World Health Organization classification of myeloid neoplasms and acute leukemia. Blood 2016;127:2391-405.

7. Killick S, Matutes E, Powles RL, et al. Outcome of biphenotypic acute leukemia. Haematologica 1999;84:699-706.

8. Park JA, Ghim TT, Bae Kw, et al. Stem cell transplant in the treatment of childhood biphenotypic acute leukemia. Pediatr Blood Cancer 2009;53:444-52.

9. Lee MY, Tan TD, Feng AC. Clinicopathologic analysis of acute myeloid leukemia in a single institution: biphenotypic acute myeloid leukemia may not be an aggressive subtype. J Chin Med Assoc 2007;70:269-73.

10. Munker R, Labopin M, Esteve J, Schmid C, Mohty M, Nagler A. Mixed phenotype acute leukemia: outcomes with allogeneic stem cell transplantation. A retrospective study from the Acute Leukemia Working Party of the EBMT. Haematologica 2017; 102:2134-40.

11. Weinberg OK, Seetharam M, Ren L, Alizadeh A, Arber DA. Mixed phenotype acute leukemia: A study of 61 cases using World Health Organization and European Group for the Immunological Classification of Leukaemias criteria. Am J Clin Pathol 2014;142: 803-8.

12. Wolach O, Stone RM. How I treat mixed-phenotype acute leukemia. Blood 2015;125:2477-85.

13. Charles NJ, Boyer DF. Mixed-phenotype acute leukemia: diagnostic criteria and pitfalls. Arch Pathol Lab Med 2017;141: 1462-8.

14. Matutes E, Pickl WF, Van't Veer M, et al. Mixed-phenotype acute leukemia: clinical and laboratory features and outcome in 100 patients defined according to the WHO 2008 classification. Blood
2011;117:3163-71

15. Gerr H, Zimmermann M, Schrappe M, et al. Acute leukaemias of ambiguous lineage in children: characterization, prognosis and therapy recommendations. Br J Haematol 2010;149:84-92.

16. Hrusak $\mathrm{O}$, de Haas $\mathrm{V}$, Stancikova J, et al. International cooperative study identifies treatment strategy in childhood ambiguous lineage leukemia. Blood 2018;132:264-76.

17. Al-Seraihy AS, Owaidah TM, Ayas M, et al. Clinical characteristics and outcome of children with biphenotypic acute leukemia. Haematologica 2009;94:1682-90.

18. Carbonell F, Swansbury J, Min T, et al. Cytogenetic findings in acute biphenotypic leukaemia. Leukemia 1996;10:1283-7.

19. Owaidah TM, Al Beihany A, Iqbal MA, Elkum N, Roberts GT. Cytogenetics, molecular and ultrastructural characteristics of biphenotypic acute leukemia identified by the EGIL scoring system. Leukemia 2006;20:620-6.

20. Xu XQ, Wang JM, Lü SQ, et al. Clinical and biological characteristics of adult biphenotypic acute leukemia in comparison with that of acute myeloid leukemia and acute lymphoblastic leukemia: a case series of a Chinese population. Haematologica 2009;94:919-27.

21. Zhang Y, Tan L, Zhang X, Wei H, Hu Q. Clinical study of acute mixed-lineage leukemia in 14 children. Iran J Pediatr 2011;21: 521-5.

22. Mikulic M, Batinic D, Sucic M, et al. Biological features and outcome of biphenotypic acute leukemia: a case series. Hematol Oncol Stem Cell Ther 2008;1:225-30.

23. Wassmann B, Pfeifer H, Goekbuget N, et al. Alternating versus concurrent schedules of imatinib and chemotherapy as front-line therapy for Philadelphia-positive acute lymphoblastic leukemia (Ph+ ALL). Blood 2006;108:1469-77.

24. Roberts KG, Li Y, Payne-Turner D, et al. Targetable kinaseactivating lesions in Ph-like acute lymphoblastic leukemia. N Engl J Med 2014;371:1005-15.

25. Yan L, Ping N, Zhu M, et al. Clinical, immunophenotypic, cytogenetic, and molecular genetic features in 117 adult patients with mixed-phenotype acute leukemia defined by WHO-2008 classification. Haematologica 2012;97:1708-12.

26. Lee JH, Min YH, Chung CW, et al. Prognostic implications of the immunophenotype in biphenotypic acute leukemia. Leuk Lymphoma 2008;49:700-9.

27. Kim HJ. Mixed-phenotype acute leukemia (MPAL) and beyond. Blood Res 2016;51:215-6.

28. Tian H, Xu Y, Liu L, et al. Comparison of outcomes in mixed phenotype acute leukemia patients treated with chemotherapy and stem cell transplantation versus chemotherapy alone. Leuk Res 2016;45:40-6.

29. Kim HN, Hur M, Kim H, et al. First case of biphenotypic/bilineal (B/myeloid, B/monocytic) mixed phenotype acute leukemia with t(9;22)(q34;q11.2);BCR-ABL1. Ann Clin Lab Sci 2016;46:435-8.

30. Shi R, Munker R. Survival of patients with mixed phenotype acute leukemias: A large population-based study. Leuk Res 2015;39: 606-16. 